\title{
Electrocatalytic Activity of Tetravalent Fe-Co Mixed Oxide for Oxygen and Hydrogen Evolution Reactions
}

\author{
Masaya Kinoshita ${ }^{1}$, Ikuya Yamada ${ }^{1, *}$, Shogo Kawaguchi ${ }^{2}$, Kengo Oka $^{3}$ and Shunsuke Yagi ${ }^{4}$ \\ ${ }^{1}$ Department of Materials Science, Graduate School of Engineering, Osaka Prefecture University, Osaka 599-8570, Japan \\ ${ }^{2}$ Japan Synchrotron Radiation Research Institute (JASRI), Hyogo 679-5198, Japan \\ ${ }^{3}$ Faculty of Science and Engineering, Kindai University, Osaka 577-8502, Japan \\ ${ }^{4}$ Institute of Industrial Science, The University of Tokyo, Tokyo 153-8505, Japan
}

Electrochemical water splitting is a useful way for sustainable hydrogen production, whereas sluggish kinetics of oxygen/hydrogen evolution reactions (OER/HER) limits the efficiency; thus, active electrocatalysts to reduce overpotentials are desired. Mixing of multiple transition-metal elements is a promising way to enhance electrochemical catalysis. In the present study, we investigated the OER and HER catalytic activities of tetravalent $\mathrm{Fe}-\mathrm{Co}$ mixed perovskite oxide $\mathrm{CaFe}_{0.5} \mathrm{Co}_{0.5} \mathrm{O}_{3}$. $\mathrm{CaFe}_{0.5} \mathrm{Co}_{0.5} \mathrm{O}_{3}$ demonstrated a higher OER activity than those of the parent compounds $\mathrm{CaFeO}_{3}$ and $\mathrm{CaCoO}_{3}$. In contrast, the HER activity of $\mathrm{CaFe}_{0.5} \mathrm{Co}_{0.5} \mathrm{O}_{3}$ was not significantly enhanced. These observations suggest that the mixing of $\mathrm{Fe}^{4+}$ and $\mathrm{Co}^{4+}$ ions is an efficient way to activate OER. [doi:10.2320/matertrans.MT-MN2019032]

(Received January 6, 2020; Accepted January 28, 2020; Published July 25, 2020)

Keywords: perovskite, oxygen evolution reaction, hydrogen evolution reaction, electrocatalyst

\section{Introduction}

Electrochemical water splitting is a useful method for sustainable hydrogen production, ${ }^{1)}$ although sluggish kinetics of oxygen/hydrogen evolution reactions (OER/HER) disturbs efficient energy conversions. ${ }^{2,3)}$ Fundamental understanding of the mechanism of OER/HER is necessary to develop efficient catalysts. Platinum-group metals and their oxides (e.g. Pt, $\mathrm{IrO}_{2}, \mathrm{RuO}_{2}$ ) have been widely utilized as practical catalysts for OER and HER to suppress intrinsic large overpotentials and resulting energy loss. ${ }^{4-6)}$ On the other hand, transition-metal oxides have been extensively investigated because of their earth abundance and low cost. ${ }^{7)}$ Exploration of novel catalysts for OER and HER has been eagerly conducted among perovskite oxide family $\left(A B \mathrm{O}_{3}\right)$, some of which display high catalytic activity. ${ }^{8-10)}$

Mixing of multiple transition-metal elements is a promising way to enhance catalytic activity, which is considered as a synergistic effect between mixed elements. For example, $\mathrm{Ba}_{0.5} \mathrm{Sr}_{0.5} \mathrm{Co}_{0.2} \mathrm{Fe}_{0.8} \mathrm{O}_{3-\delta}$ (BSCF) is proposed as a highly active OER catalyst ${ }^{8)}$ and further mixing of multiple transition metals enhances stability. ${ }^{10)}$ However, the origin of the synergistic effect has not been elucidated well because of complex chemical compositions and crystal structures including substantial amount of oxygen deficiency. ${ }^{11)}$ Suntivich et al. also proposed electron occupancy in the $\mathrm{e}_{\mathrm{g}}$ orbital of the transition metal ion at $B$ site in the perovskite structure can be a simple descriptor; the catalytic activity of BSCF $\left(\mathrm{e}_{\mathrm{g}} \sim 1.2\right)$ locates at the top of the volcano-like plot as a function of $\mathrm{e}_{\mathrm{g}}$ electron number. ${ }^{8)}$ On the other hand, it has been recently suggested that the oxygen deficiencies in the perovskite-related phases also play an important role in promoting OER. ${ }^{9)}$ A brownmillerite oxide $\mathrm{Ca}_{2} \mathrm{FeCoO}_{5}$ consisting of randomly mixed $\mathrm{Fe}$ and $\mathrm{Co}$ ions displays a high catalytic activity for OER, ${ }^{12-14)}$ implying that tetrahedral $\left(\mathrm{Fe}^{3+} / \mathrm{Co}^{3+}\right) \mathrm{O}_{4}$ and octahedral $\left(\mathrm{Fe}^{3+} / \mathrm{Co}^{3+}\right) \mathrm{O}_{6}$ units affect

*Corresponding author, E-mail: yamada@mtr.osakafu-u.ac.jp catalytic activity for OER in addition to the mixing of $\mathrm{Fe}^{3+}$ and $\mathrm{Co}^{3+}$ ions. It is expected that the mixing of intrinsically active ions such as $\mathrm{Fe}^{4+}$ and $\mathrm{Co}^{4+}$ further improves the electrochemical catalysis of perovskite oxides for OER, ${ }^{15)}$ but detailed study has not been conducted yet because of the difficulty in synthesis of high-valent metal oxides under ambient conditions. In the present study, we synthesized $\mathrm{CaBO}_{3}\left(B=\mathrm{Fe}, \mathrm{Co}\right.$, and $\left.\mathrm{Fe}_{0.5} \mathrm{Co}_{0.5}\right)$ under high-pressure and high-temperature conditions at $8 \mathrm{GPa}$ and $1373 \mathrm{~K}$ to examine the coexistence effects of randomly mixed $\mathrm{Fe}^{4+}$ and $\mathrm{Co}^{4+}$ ions on OER and HER catalysts. The OER catalytic activity was significantly improved by mixing $\mathrm{Fe}^{4+}$ and $\mathrm{Co}^{4+}$ ions in $\mathrm{CaFe}_{0.5} \mathrm{Co}_{0.5} \mathrm{O}_{3}$ whereas a smaller enhancement was observed for HER. This finding proposes the mixing of high-valent $\mathrm{Fe}^{4+}$ and $\mathrm{Co}^{4+}$ ions is a useful way for activating OER rather than HER.

\section{Experimental Procedure}

The powder sample of $\mathrm{CaFe}_{0.5} \mathrm{Co}_{0.5} \mathrm{O}_{3}$ was synthesized from its stoichiometric mixture, which was prepared by complex polymerized method in advance. ${ }^{16)}$ High-pressure and high-temperature treatment ( $8 \mathrm{GPa}$ and $1373 \mathrm{~K}$ ) with a oxidizing agent $\mathrm{KClO}_{4}$ was utilized to stabilize $\mathrm{Fe}^{4+}$ and $\mathrm{Co}^{4+}$ valence states for $\mathrm{CaBO} \mathrm{O}_{3}\left(B=\mathrm{Fe}, \mathrm{Co}\right.$, and $\left.\mathrm{Fe}_{0.5} \mathrm{Co}_{0.5}\right)$ without oxygen deficiency. X-ray powder diffraction patterns at room temperature were collected using a X-ray diffractometer with $\mathrm{Cu} \mathrm{K} \alpha$ a radiation (Ultima IV, Rigaku, Japan). Specific surface area was estimated by the BrunauerEmmett-Teller (BET) analysis of $\mathrm{Kr}$ gas adsorption data. Specific surface area was determined by BET analysis of Kr-gas absorption data. Oxidation states of the constituent transition metal ions were determined by iodometric titration with Hiranuma automatic titrator (COM-1700A, Hiranuma, Japan).

OER catalytic activity was evaluated by using rotating disk electrode system (RRDE-3A, BAS, Japan) in the same manner as the previous studies. ${ }^{15,17,18)}$ Electrochemical 


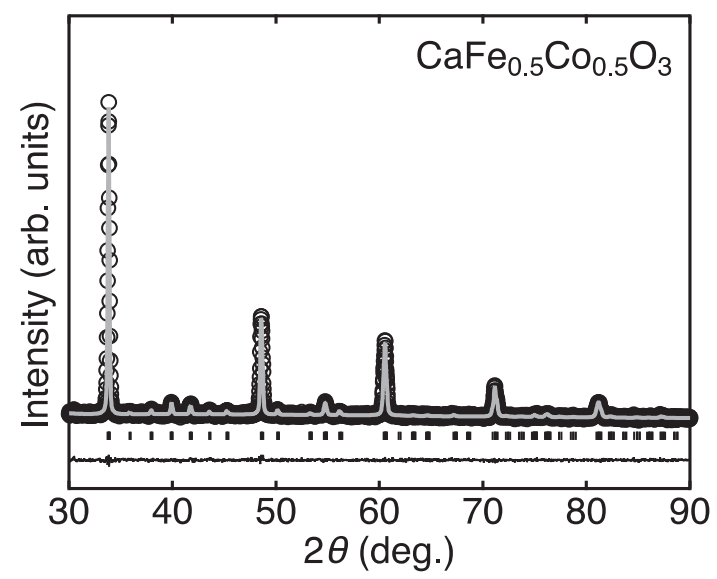

Fig. 1 Observed XRD pattern of $\mathrm{CaFe}_{0.5} \mathrm{Co}_{0.5} \mathrm{O}_{3}$ and the Rietveld refinement result. The circles and solid lines represent observed and calculated patterns, respectively. The difference between the observed and calculated patterns is shown at the bottom. The vertical marks indicate the Bragg reflection positions.

measurements were conducted in $1 \mathrm{M} \mathrm{KOH}$ solution under $\mathrm{O}_{2}$ saturation (for OER) and $\mathrm{N}_{2}$ saturation (for HER) at room temperature.

\section{Results and Discussions}

Figure 1 shows the XRD pattern and Rietveld refinement result of $\mathrm{CaFe}_{0.5} \mathrm{Co}_{0.5} \mathrm{O}_{3}$. All the Bragg reflection peaks were indexed with the $\mathrm{GdFeO}_{3}$-type orthorhombic perovskite structure with the space group of Pnma (No. 62). Based on the refinement, the lattice constants were determined to be $a=5.3106(5) \AA, b=7.4850(7) \AA, c=5.2921(5) \AA$. The calculated unit cell volume (210.36(3) $\left.\AA^{3}\right)$ for $\mathrm{CaFe}_{0.5} \mathrm{Co}_{0.5} \mathrm{O}_{3}$ was an intermediate value between $\mathrm{CaFeO}_{3}\left(214.97 \AA^{3}\right)$ and $\mathrm{CaCoO}_{3}\left(207.65 \AA^{3}\right)$, confirming that the obtained oxide is the $1: 1$ solid solution of $\mathrm{CaFeO}_{3}$ and $\mathrm{CaCoO}_{3} \cdot{ }^{19,20)}$ $\mathrm{CaFe}_{0.5} \mathrm{Co}_{0.5} \mathrm{O}_{3}$ probably consists of $\mathrm{Fe}^{4+}\left(\mathrm{t}_{2 \mathrm{~g}}{ }^{3} \mathrm{e}_{\mathrm{g}}{ }^{1}\right.$ configuration) and $\mathrm{Co}^{4+}\left(\mathrm{t}_{2 \mathrm{~g}}{ }^{4} \mathrm{e}_{\mathrm{g}}{ }^{1}\right.$ configuration) ions as well as the parent compounds. ${ }^{19,20)}$ Since there was no sign of additional peaks attributed to atomic ordering, $\mathrm{Fe}$ and $\mathrm{Co}$ ions are distributed randomly at the same crystallographic sites. Oxygen content for $\mathrm{CaFe}_{0.5} \mathrm{Co}_{0.5} \mathrm{O}_{3}$ was determined to be about 2.98 by iodometric titration, confirming the tetravalency of the transition metals.

Figure 2 shows linear sweep voltammograms in OER conditions for $\mathrm{CaBO}_{3}\left(B=\mathrm{Fe}, \mathrm{Co}\right.$, and $\left.\mathrm{Fe}_{0.5} \mathrm{Co}_{0.5}\right)$. Current densities per surface area of oxides (in a unit of $\mathrm{mA} \mathrm{cm}{ }_{\text {oxide }}^{-2}$ were adopted to evaluate the intrinsic catalytic activities. The OER onset potentials $\left(E_{\mathrm{OER}}\right)$ were determined using the potentials reaching $1 \mathrm{~mA} \mathrm{~cm}^{-2}$, and OER overpotentials $\left(\eta_{\mathrm{OER}}\right)$ were calculated as follows: $\eta_{\mathrm{OER}}=E_{\mathrm{OER}}$ $-1.23 \mathrm{~V}$. The overpotential of $\mathrm{CaFeO}_{3}\left(\eta_{\mathrm{OER}}=0.39 \mathrm{~V}\right)$ for OER was superior to that of $\mathrm{CaCoO}_{3}\left(\eta_{\text {OER }}=0.47 \mathrm{~V}\right)$ as well as the previous study measured in $0.1 \mathrm{M} \mathrm{KOH}$ conditions. ${ }^{18)}$ $\mathrm{CaFe}_{0.5} \mathrm{Co}_{0.5} \mathrm{O}_{3}$ exhibited a lower overpotential $\left(\eta_{\mathrm{OER}}=\right.$ $0.31 \mathrm{~V}$ ) than both $\mathrm{CaFeO}_{3}$ and $\mathrm{CaCoO}_{3}$, clearly indicating a significant $\mathrm{Fe}^{4+}-\mathrm{Co}^{4+}$ mixing effect on OER activity. It is notable that the present result cannot be explained by other descriptors such as $\mathrm{e}_{\mathrm{g}}$ electron configuration and oxygen deficiency because the $\mathrm{e}_{\mathrm{g}}$ electron for $\mathrm{CaFe}_{0.5} \mathrm{Co}_{0.5} \mathrm{O}_{3}$ is

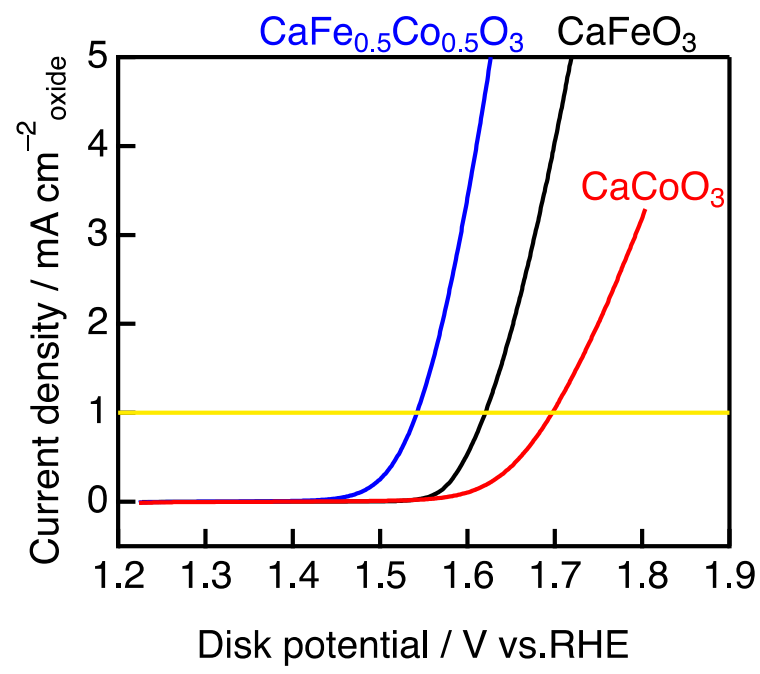

Fig. 2 Linear sweep voltammograms in OER conditions for $\mathrm{CaBO}_{3}$ ( $B=\mathrm{Fe}, \mathrm{Co}$, and $\mathrm{Fe}_{0.5} \mathrm{Co}_{0.5}$ ). The disk potential was controlled between 0.3 and $0.9 \mathrm{~V}$ versus $\mathrm{Hg} / \mathrm{HgO}$ at a scan rate of $10 \mathrm{mV} \mathrm{s}^{-1}$ and the disk rotation rate was set at $1600 \mathrm{rpm}$.

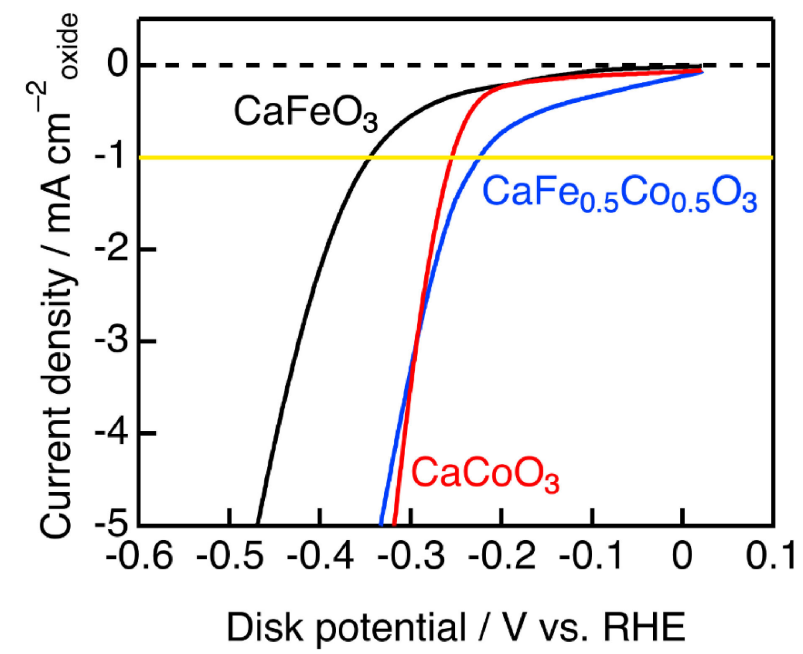

Fig. 3 Linear sweep voltammograms in HER conditions for $\mathrm{Ca}_{3} \mathrm{O}_{3}(B=$ $\mathrm{Fe}, \mathrm{Co}$, and $\mathrm{Fe}_{0.5} \mathrm{Co}_{0.5}$ ). The disk potential was controlled between -0.9 and $-1.5 \mathrm{~V}$ versus $\mathrm{Hg} / \mathrm{HgO}$ at a scan rate of $10 \mathrm{mV} \mathrm{s}^{-1}$ and the disk rotation rate was set at $1600 \mathrm{rpm}$.

retained in the mixture of $\mathrm{Fe}^{4+}\left(\mathrm{t}_{2 \mathrm{~g}}{ }^{3} \mathrm{e}_{\mathrm{g}}{ }^{1}\right)$ and $\mathrm{Co}^{4+}\left(\mathrm{t}_{2 \mathrm{~g}}{ }^{4} \mathrm{e}_{\mathrm{g}}{ }^{1}\right)$ with identical $\mathrm{e}_{\mathrm{g}}$ electron number.

Figure 3 shows linear sweep voltammograms in HER conditions for $\mathrm{CaBO}_{3}\left(B=\mathrm{Fe}, \mathrm{Co}\right.$, and $\left.\mathrm{Fe}_{0.5} \mathrm{Co}_{0.5}\right)$. HER overpotentials $\left(\eta_{\mathrm{HER}}\right)$ were determined based on the absolute values of the onset potentials reaching at $-1 \mathrm{~mA} \mathrm{~cm}^{-2}\left(E_{\mathrm{HER}}\right.$; $\left.\eta_{\mathrm{HER}}=\left|E_{\mathrm{HER}}\right|\right)$, as well as $\eta_{\mathrm{OER}}$. The HER overpotential of $\mathrm{CaCoO}_{3}$ for HER $\left(\eta_{\mathrm{HER}}=0.26 \mathrm{~V}\right)$ was lower than that of $\mathrm{CaFeO}_{3}\left(\eta_{\mathrm{HER}}=0.35 \mathrm{~V}\right)$ in contrast to OER overpotentials. The disagreement between OER and HER activity implies that the descriptors for each reaction are different. Since systematic trend in HER activity for perovskite oxides has not been elucidated yet, we do not focus on the detailed HER mechanism in this study. $\mathrm{CaFe}_{0.5} \mathrm{Co}_{0.5} \mathrm{O}_{3}$ exhibited a lower overpotential $\left(\eta_{\mathrm{HER}}=0.22 \mathrm{~V}\right)$ than $\mathrm{CaFeO}_{3}$, but almost the same as $\mathrm{CaCoO}_{3}$. This is apparent from the result that both the voltammograms of $\mathrm{CaFe}_{0.5} \mathrm{Co}_{0.5} \mathrm{O}_{3}$ and $\mathrm{CaCoO}_{3}$ are 
almost overlapping. These observations indicate that the synergistic effect of the $\mathrm{Fe}^{4+}-\mathrm{Co}^{4+}$ mixing is subtle on HER activity in contrast to the significant increase in the OER activity of $\mathrm{CaFe}_{0.5} \mathrm{Co}_{0.5} \mathrm{O}_{3}$.

\section{Conclusion}

We successfully synthesized the $\mathrm{Fe}^{4+}-\mathrm{Co}^{4+}$ mixed oxide $\mathrm{CaFe}_{0.5} \mathrm{Co}_{0.5} \mathrm{O}_{3}$ using a high-pressure synthesis method, exhibiting that the OER catalytic activity is significantly improved by mixing $\mathrm{Fe}^{4+}$ and $\mathrm{Co}^{4+}$ ions. This work first demonstrated the synergistic effect between $\mathrm{Fe}^{4+}$ and $\mathrm{Co}^{4+}$ on the OER activity. In contrast, the HER activity was slightly enhanced by $\mathrm{Fe}^{4+}-\mathrm{Co}^{4+}$ mixing. This finding suggests a simple and new design principle to enhance the OER catalysis rather than HER catalysis.

\section{Acknowledgments}

This work was supported by JSPS KAKENHI (grant number $18 \mathrm{H} 03835$ and $19 \mathrm{H} 02438)$.

\section{REFERENCES}

1) M. Carmo, D.L. Fritz, J. Mergel and D. Stolten: Int. J. Hydrogen Energ. 38 (2013) 4901-4934.

2) W.T. Hong, M. Risch, K.A. Stoerzinger, A. Grimaud, J. Suntivich and Y. Shao-Horn: Energy Environ. Sci. 8 (2015) 1404-1427.

3) R. Subbaraman, D. Tripkovic, D. Strmcnik, K.C. Chang, M. Uchimura, A.P. Paulikas, V. Stamenkovic and N.M. Markovic: Science 334 (2011) 1256-1260.

4) R.R. Rao et al.: Energy Environ. Sci. 10 (2017) 2626-2637.
5) Y. Lee, J. Suntivich, K.J. May, E.E. Perry and Y. Shao-Horn: J. Phys. Chem. Lett. 3 (2012) 399-404.

6) S. Trasatti: Electrochim. Acta 29 (1984) 1503-1512.

7) A.A. El-Moneim, N. Kumagai and K. Hashimoto: Mater. Trans. 50 (2009) 1969-1977.

8) J. Suntivich, K.J. May, H.A. Gasteiger, J.B. Goodenough and Y. ShaoHorn: Science 334 (2011) 1383-1385.

9) K.J. May, C.E. Carlton, K.A. Stoerzinger, M. Risch, J. Suntivich, Y.L. Lee, A. Grimaud and Y. Shao-Horn: J. Phys. Chem. Lett. 3 (2012) 3264-3270.

10) Y. Zhu, W. Zhou, Z.G. Chen, Y. Chen, C. Su, M.O. Tadé and Z. Shao: Angew. Chem. Int. Ed. 54 (2015) 3897-3901.

11) I. Yamada, T. Odake, K. Asai, K. Oka, S. Kawaguchi, K. Wada and S. Yagi: Mater. Chem. Front. 3 (2019) 1209-1217.

12) E. Tsuji, T. Motohashi, H. Noda, D. Kowalski, Y. Aoki, H. Tanida, J. Niikura, Y. Koyama, M. Mori, H. Arai, T. Ioroi, N. Fujiwara, Y. Uchimoto, Z. Ogumi and H. Habazaki: ChemSusChem 10 (2017) 2864-2868.

13) K. Nakayama, R. Ishikawa, A. Kuwabara, S. Kobayashi, T. Motohashi, N. Shibata and Y. Ikuhara: Inorg. Chem. 58 (2019) 10209-10216.

14) D. Kowalski, H. Kiuchi, T. Motohashi, Y. Aoki and H. Habazaki: ACS Appl. Mater. 11 (2019) 28823-28829.

15) I. Yamada, A. Takamatsu, K. Asai, T. Shirakawa, H. Ohzuku, A. Seno, T. Uchimura, H. Fujii, S. Kawaguchi, K. Wada, H. Ikeno and S. Yagi: J. Phys. Chem. C 122 (2018) 27885-27892.

16) M. Kakihana: J. Sol-Gel Sci. Technol. 6 (1996) 7-55.

17) S. Yagi, I. Yamada, H. Tsukasaki, A. Seno, M. Murakami, H. Fujii, H. Chen, N. Umezawa, H. Abe, N. Nishiyama and S. Mori: Nat. Commun. 6 (2015) 8249

18) I. Yamada, A. Takamatsu, K. Asai, H. Ohzuku, T. Shirakawa, T. Uchimura, S. Kawaguchi, H. Tsukasaki, S. Mori, K. Wada, H. Ikeno and S. Yagi: ACS Appl. Energy Mater. 1 (2018) 3711-3721.

19) P.M. Woodward, D.E. Cox, E. Moshopoulou, A.W. Sleight and S. Morimoto: Phys. Rev. B 62 (2000) 844-855.

20) T. Osaka, H. Takahashi, H. Sagayama, Y. Yamasaki and S. Ishiwata: Phys. Rev. B 95 (2017) 224440. 